\title{
1 A horizon scan of emerging issues for global conservation in 2019
}

2 William J. Sutherland ${ }^{1 *}$, Steven Broad ${ }^{2}$, Stuart H.M. Butchart ${ }^{3,1}$, Stewart J. Clarke ${ }^{4}$, Alexandra M.

3 Collins $^{5}$, Lynn V. Dicks ${ }^{6}$, Helen Doran ${ }^{7}$, Nafeesa Esmail ${ }^{8}$, Erica Fleishman ${ }^{9}$, Nicola Frost ${ }^{10}$, Kevin J.

4 Gaston $^{11}$, David W. Gibbons ${ }^{12}$, Alice C. Hughes ${ }^{13}$, Zhigang Jiang ${ }^{14,}{ }^{15}$, Ruth Kelman ${ }^{16}$, Becky

5 LeAnstey ${ }^{17}$, Xavier le Roux ${ }^{18,19}$, Fiona A. Lickorish ${ }^{20}$, Kathryn A. Monk ${ }^{21}$, Diana Mortimer22, James W.

6 Pearce-Higgins ${ }^{23,1}$, Lloyd S. Peck ${ }^{24}$, Nathalie Pettorelli ${ }^{25}$, Jules Pretty ${ }^{26}$, Colleen L. Seymour ${ }^{27}$, Mark D.

7 Spalding ${ }^{28}$, Jonathan Wentworth ${ }^{29}$ and Nancy Ockendon ${ }^{1}$

$8 \quad{ }^{1}$ Conservation Science Group, Department of Zoology, Cambridge University, The David

$9 \quad$ Attenborough Building, Pembroke Street, Cambridge, CB2 3QZ, UK

10 2TRAFFIC, The David Attenborough Building, Pembroke Street, Cambridge, CB2 3QZ, UK

11 3BirdLife International, The David Attenborough Building, Pembroke Street, Cambridge, CB2 3QZ,

12 UK

$13{ }^{4}$ The National Trust, Heelis, Kemble Drive, Swindon, SN2 2NA, UK

$14{ }^{5}$ Centre for Environmental Policy, Imperial College, London, UK

$15{ }^{6}$ School of Biological Sciences, University of East Anglia, Norwich, NR4 7TJ, UK

$16{ }^{7}$ Natural England, Eastbrook, Shaftesbury Road, Cambridge, CB2 8DR, UK

$17{ }^{8}$ Oxford Martin Programme on the Illegal Wildlife Trade, 34 Broad St, Oxford, OX1 3BD, UK

${ }^{9}$ Department of Fish, Wildlife and Conservation Biology, Colorado State University, Fort Collins, CO

19 80523, USA

${ }^{10}$ Fauna \& Flora International, The David Attenborough Building, Pembroke Street, Cambridge CB2

$213 Q Z$, UK

$22{ }^{11}$ Environment and Sustainability Institute, University of Exeter, Penryn Campus, Penryn, Cornwall,

23 TR10 9FE, UK 
${ }^{12}$ RSPB Centre for Conservation Science, Royal Society for the Protection of Birds, The Lodge, Sandy,

SG19 2DL, UK and The David Attenborough Building, Pembroke Street, Cambridge CB2 3QZ, UK

$26{ }^{13}$ Centre for Integrative Conservation, Xishuangbanna Tropical Botanical Garden, Chinese Academy

of Sciences, Xishuangbanna, Yunnan, 666303, P.R. China

$28{ }^{14}$ Institute of Zoology, Chinese Academy of Sciences, Beijing, 100101, P.R. China

${ }^{15}$ University Chinese Academy of Sciences, Beijing, 100049, P.R. China

${ }^{16}$ Natural Environment Research Council, Polaris House, North Star Avenue, Swindon, SN2 1EU, UK

${ }^{17}$ Environment Agency, Horizon House, Deanery Road, Bristol, BS1 5AH, UK

${ }^{18}$ Microbial Ecology Centre, UMR1418 INRA, CNRS, University Lyon 1, 69622 Villeurbanne, France

${ }^{19}$ La Fondation pour la recherche sur la biodiversité, 195 rue Saint Jacques, 75005 Paris, France

${ }^{20}$ UK Research and Consultancy Services (RCS) Ltd, Valletts Cottage, Westhope, Hereford, HR4 8BU,

${ }^{21}$ Natural Resources Wales, Cambria House, 29 Newport Road, Cardiff, CF24 OTP, UK

${ }^{22}$ Joint Nature Conservation Committee, Monkstone House, City Road, Peterborough, PE1 1UA, UK

${ }^{23}$ British Trust for Ornithology, The Nunnery, Thetford, IP24 2PU, UK

${ }^{24}$ British Antarctic Survey, Natural Environment Research Council, High Cross, Madingley Road, Cambridge, CB3 OET, UK

${ }^{25}$ Institute of Zoology, Zoological Society of London, Regent's Park, London, NW1 4RY, UK

${ }^{26}$ School of Biological Sciences, University of Essex, Colchester, CO4 3SQ, UK

${ }^{27}$ South African National Biodiversity Institute, Private Bag X7, Claremont 7735, South Africa

${ }^{28}$ Global Marine Team, The Nature Conservancy, Department of Physical, Earth and Environmental Sciences, University of Siena, Pian dei Mantellini, Siena 53100, Italy

${ }^{29}$ Parliamentary Office of Science and Technology, 14 Tothill Street, Westminster, London, SW1H 9NB 
$49 *$ *Correspondence: Sutherland, W.J. (w.sutherland@zoo.cam.ac.uk) 


\section{Abstract}

51

52 We present the results of our tenth annual horizon scan. We identified 15 emerging priority topics

53 that may have major positive or negative effects on the future conservation of global biodiversity,

54 but which at present, have low awareness within the conservation community. We thus hope to

55 focus increased research and policy attention on these areas, improving the capacity of the

56 community to mitigate impacts of issues likely to have negative effects, and maximise the benefits

57 of issues that provide opportunities. The topics include advances in crop breeding, which may affect

58 insects and land use; manipulations of natural water flows and weather systems on the Tibetan

59 Plateau; release of carbon and mercury from melting polar ice and thawing permafrost; new

60 funding schemes and regulations; and land-use changes across Indo-Malaysia.

61

62

63

64 
Aims of horizon scanning

We present the 15 topics identified in our tenth annual horizon scan of emerging issues that are likely to be relevant to global conservation. These are issues that could have significant impacts on society's ability to conserve regional or global biodiversity, but for which the conservation community currently has generally low awareness. These topics were identified by a group of 28 participants, including experts in futures research and horizon scanning, advisors to policy-makers, researchers, and practitioners of conservation and other aspects of environmental science. The areas highlighted are highly varied, ranging from major infrastructure projects and new technological developments, to new funding schemes and regulations that are likely to transform food production and land use.

We aim to draw the attention of the global conservation community to the potential opportunities and risks associated with these issues. We hope that by raising awareness, we will encourage research, discussion, and allocation of funds, in addition to management and policy change, resulting in improved understanding and greater preparedness. This could facilitate the global conservation community and wider society to respond effectively to the development of these issues. Our work therefore may inform researchers, funding bodies, policy makers, regulatory bodies, conservation organisations and practitioners.

Our approach is supported by the maturing of many issues from previous scans. For example, overexploitation of sand resources was highlighted by Sutherland et al. [1], and subsequent evidence has demonstrated that sand extraction has negative effects on seagrass meadows, nesting terrapins, and migratory waterbirds [2]. In another example, WWF, in partnership with fisheries and technology companies, has implemented a pilot project that uses blockchain technology (identified in [1]) to trace tuna from capture to distribution in an attempt to reduce illegal and unregulated fishing[3]. Discussions continue about extending the application of blockchain to a wide range of other supply 
89 chains (e.g., timber [4]). In January 2018, the European Parliament voted to ban the use of electric currents for commercial fishing (electric pulse trawling) [5], a topic raised by Sutherland et al. [6].

91 Although in practice electric pulse trawling is continuing much as it did before the vote, the swift political action may imply that awareness of the practice and its environmental effects was relatively high in the research and European policy arenas. By increasing recognition of the issues described in this paper, we aim to encourage dialogue about their potential negative and positive impacts on conservation, in order to guide proactive solutions and harness future opportunities.

\section{Identification of Issues}

Our methods for this horizon scan were consistent with those used in our previous nine annual scans

(for example see [7, 8], Figure 1). The 28 core participants (the authors) used a modified version of the Delphi technique that is repeatable, inclusive, and transparent $[9,10]$. Participants' expertise covered diverse conservation-related disciplines, including marine, freshwater and terrestrial ecology; agriculture and land use; microbiology; conservation practice and technology; sustainability; environmental management; policy; economics; research programming; science communication; and professional horizon scanning. The participants were affiliated with academia, government, and non-governmental organisations.

Participants consulted their professional networks one-on-one, via wider conversations and requests 109 at meetings, and through targeted social media and group email requests. We consulted 110 approximately 495 people during the initial stage of issue identification, leading to the submission of 11191 issues. The criteria used for considering the suitability of topics for submission to the exercise 112 were: novelty (or, for better-known issues, a marked change in the intensity or nature of their impact 
113 that was considered novel or poorly known); the potential for major positive or negative effects on 114 the conservation of global or regional biological diversity in the future; and a reasonable likelihood 115 that the importance of the topic would increase.

117 We grouped submissions that addressed a similar issue together and scored variations of the same 118 issue collectively. The long list of 91 issues was circulated to participants, who scored each issue from $1190-1000$ on the basis of both its novelty and the potential magnitude of its effects; they also recorded 120 whether they had previously been aware of each issue. Participants were given the option of adding 121 comments on each topic related to the criteria. For example, frequent comments from participants 122 included issues already being too well known, issues being similar to or linked to each other, or issues 123 being too far from realisation to be plausible. To counter possible scoring fatigue, or unconscious 124 differences in scoring of issues near the start and end of a long list [11], the order in which issues were presented differed among the participants. Each individual's scores were used to rank the issues. The 35 issues with the highest median ranks, along with any comments, were retained for round-table discussion in Cambridge (United Kingdom) in September 2018. After this initial scoring, participants were given the opportunity to retain any issues that they thought had been undervalued; one issue was retained during this process. A new issue that had emerged in the global news media during this period also was presented, giving a total of 37 issues for consideration during the meeting 131 (Figure 1).

133 Prior to the round-table discussion, two participants were assigned to each of the 37 topics (three to 134 the newly-suggested topic) to further investigate its novelty, likelihood of occurrence or implementation, and likely magnitude of positive or negative effects. During the meeting, each topic in turn was discussed in relation to the criteria for inclusion. The rank from the initial round of scoring 
and the proportion of participants that were aware of the topic were considered in the discussion.

138 During the discussion of some topics, the emphasis was adjusted, or additional points and sources of 139 information were included. Following discussion of each topic, all participants independently and 140 confidentially rescored the topic. The 15 issues with the highest median ranks at the end of the 141 meeting are presented here, grouped thematically rather than in rank order.

The 2019 Issues

\section{Change in the capacity of Antarctic benthos to store carbon as climate changes}

147 The Antarctic is losing ice faster than previously projected. Gigatonnes of ice sheet are being lost extent than anything seen previously, smothering benthic communities in bays and fjords around the continent. Additionally, rapid loss of sea ice may mediate increases in phytoplankton and heighten the potential for iceberg-seabed collisions (or ice scour), associated with high zoobenthos mortality [13]. The seabed on the polar continental shelves is among the largest sinks of oceanic, or blue, carbon on Earth [14], and the functioning of its ecosystems could substantially shape the global carbon cycle and rate of climate change. The two opposing factors acting on oceanic carbon could result in different outcomes, and the balance between the two is unpredictable. The current expectation is that an increase in organisms on the vast, warming sub-Antarctic shelves likely will 158 increase oceanic carbon storage, which could become the single largest negative feedback on climate change. However, opposing this is a likely loss of carbon in regions of scouring where of giant icebergs are frequently grounded, emphasizing the complexity and uncertainty surrounding this issue [14]. 


\section{Extensive release of mercury by thawing permafrost}

Mercury is a highly toxic element that is released from both natural and anthropogenic sources. It accumulates in aquatic and terrestrial food chains, and negative effects have been demonstrated on animal neurology and reproduction, plant growth and soil microbial function (e.g. $[15,16])$. Although the potential for release of mercury from thawing permafrost is known [17], two recent studies concluded that the magnitude of the release could be far greater than was previously thought. Olson et al. [18] estimated that 408000 tonnes of mercury is stored in the active layer of the northern hemisphere permafrost while Schuster et al. [19] estimated approximately double this quantity, 863 000 tonnes, with an additional 793000 tonnes in the permanently frozen layers. The latter total of 1 656000 tonnes is roughly twice that of the global aggregate across all other soils, oceans, and the atmosphere. Given that climate change could cause much of the permafrost to thaw over the next century, most of this accumulation of mercury will be transported from soil, via streams and rivers, to the oceans. This could have potentially far-reaching impacts on terrestrial and aquatic organisms that could be acute, through chronic bioaccumulation or microbial conversion to the highly toxic methyl mercury. Already, mercury concentrations in the Yukon River are some 3-32 times higher than reported for eight other major northern hemisphere rivers [20].

\section{Ecological effects of options for reducing plastic pollution}

Public concern over plastic pollution and its effects on wildlife have dramatically increased. This has resulted in widespread interest by the public, governments and businesses in options for reducing the volume of plastics used and discarded. Novel ongoing research into reducing impacts of conventional plastic waste is developing improvements to recycling technology [21] and the use of newly discovered microbes or enzymes to biodegrade conventional plastics [22]. Other approaches, 
such as the production of novel materials including biomass-derived plastic, may have unintended impacts. For example, substitutes such as polylactide (PLA) use maize (Zea mays) or switchgrass (Panicum spp.) as a feedstock, and, if produced on a large scale, could affect food and water security, as well as the available area of habitat for native species. Biodegradation of PLA under natural environmental conditions is also very slow, taking between 100 and 1000 years [23]. Life-cycle assessments have not been applied to many of these new materials to evaluate the trade-offs of switching from conventional plastics. Furthermore, seeking substitutes for plastics may prevent public awareness of the benefits of reducing overall consumption.

\section{Effects of shinorine sunscreens on corals and other marine species}

The amino acid shinorine, which strongly absorbs ultraviolet light and hence has potential for use in sunscreens, has recently been produced using a synthetic biology approach [24]. Shinorine is currently produced from wild-harvested algae (Porphyra umbilicalis), but the new process has inserted a gene cluster from the filamentous cyanobacterium Fischerella into the freshwater cyanobacteria Synechocystis, yielding titres commensurate with commercial use [24]. Many conventional sunscreens currently contain oxybenzone and octinoxate, which are thought to contribute to coral reef bleaching through direct toxicity and increased risk of viral infection in coral [25]. As a result, there is considerable interest in developing new sunscreens that do not have negative effects on corals. However, shinorine has wider biological effects, such as stimulating inflammatory responses in humans [26]. The potential effects on marine organisms of extensive adoption of shinorine in sunscreen products are unknown.

A new irrigation canal in northwest China supplied by water from the Qinghai-Tibet Plateau 
208 A newly proposed canal, the Hongqi River, has gained traction as a mechanism to irrigate 209 agriculturally unproductive semi-desert in northern China [27]. The planned 6,188 km canal would 210 divert freshwater from the Yarlung-Zangbo River, and travel along the eastern edge of the Qinghai211 Tibetan plateau to Xinjiang. The annual water flow could be 60 billion $\mathrm{m}^{3}$, equivalent to the annual runoff of the Yellow River, which would irrigate an area of approximately $200000 \mathrm{~km}^{2}$. To date, environmental impact assessments have not been published, yet this project could have substantial ecological effects. First, there may be direct impacts on native species and ecosystems [28] through irrigation and conversion to agriculture. Second, changing patterns of river connectivity and hydrological regimes may impact in-stream and riparian ecology and affect regional land cover by reducing water flow over huge areas. Third, water extraction on this scale is likely to affect the downstream ecology of the Yarlung-Zangbo River in India, Bangladesh and elsewhere. Such changes could have dramatic impacts on biodiversity [28] and regional climate, including precipitation patterns. They could also cause a major shift in human settlement patterns, with up to 100000 people directly displaced. Furthermore, changes in hydrology may increase the probability of earthquakes [29]. Although the canal is still conceptual, proposals have been announced publicly, and further development seems plausible [29].

\section{Modification of weather in the Tibetan Plateau by cloud seeding}

227 China's state-run Aerospace Science and Technology Corporation has announced plans to build an extensive network of cloud-seeding devices on the mountain ridges lining the Tibetan Plateau [30].

229 The project has been made possible through the application of military rocket technology, controlled by a satellite network. These rockets can burn high-density fuel in low-oxygen, high-elevation environments and release silver iodide particles into the atmosphere [31]. These particles act as 
condensation nuclei that crystallize cloud vapour to induce precipitation. With plans to cover 1.6 million $\mathrm{km}^{2}$, this could add 10 billion $\mathrm{m}^{3}$ of water each year to the current annual rainfall of 200-500 $\mathrm{mm}$, with the potential to alter substantially the weather over large areas. If implemented, cloud seeding could have considerable effects on the semi-arid alpine ecosystems of the region, increasing loss of the current alpine cold steppe and meadow habitats and threatening many endemic species in the region. Additionally, there are concerns that altering current weather patterns could affect water availability from some of Asia's major rivers, on which 1.4 billion people currently depend.

\section{Salt-tolerant strains of rice}

Rising sea-levels and irrigation have driven the salinization of both coastal and inland agricultural soils, leading agronomists to seek to develop salt-tolerant strains of staple crops. This has included a recent intensive drive to use genetic technology to develop salt-tolerant rice (Oryza sativa) in China (for example, [32]), and a recent collaboration between China and Dubai may have increased the likelihood of its commercial cultivation in halophytic regions. New strains of rice have yielded over $6.0 \mathrm{t} / \mathrm{ha}$ [33] when irrigated with dilute seawater; this is comparable to commercial yields in many rice-growing regions of the world [34]. If these yields are transferable to larger areas, rice production could become feasible on saline and alkaline soils that currently cannot support this cereal. According to the Agriculture Department of China there were approximately 34 million ha of saline-alkali land in China at the end of 2015 [35]. If large-scale cultivation is undertaken, appropriation of additional freshwater will still be necessary as the salinity of water used in the Dubai experiments was a tenth that of seawater. Salinization and other ecological effects of conversion of natural ecosystems to commercial cultivation of salt-tolerant rice, especially in coastal areas and continental inland salt steppe, have not been fully explored. 


\section{US government decision not to regulate gene-edited plants}

259 Gene editing using novel techniques such as clustered regularly interspaced short palindromic 260 repeats (CRISPR) can introduce plant traits more quickly and precisely than traditional methods, potentially increasing crop productivity. For example, a team in China recently developed a variety of rice that yielded $25-31 \%$ more grain than non-edited rice in field tests [36]. It may also be used to transform species that have not formerly been utilised by humans into new crops via targeted changes to plant toxicity, fruit size, nutritional content or growth conditions [37]. In March 2018, the US Department of Agriculture announced that it had no plans to regulate gene editing of plants that otherwise could be developed via traditional breeding techniques [38]. By contrast, the European 267 Court of Justice stated in July 2018 that gene-edited crops should be subject to the same stringent regulations that apply to genetically modified organisms [39]. Despite the European Union ruling, the absence of US regulation is likely to catalyse innovation in gene-editing, and research is currently underway to improve efficiency, without introducing other genomic changes that have unintended and undesirable consequences. Depending on the specifics of the gene-edited plants and associated

272 production systems, effects on biodiversity could be positive or negative. These could range from 273 reductions in agro-chemicals usage and the area needed for crop production, to further 274 intensification of cropping and forestry systems and unforeseen effects on native species, and 275 increases in use of various agro-chemicals if resistant crop varieties are developed. 
279 Oilseed varieties have recently been genetically engineered to produce the omega-3 fatty acids eicosapentaenoic acid (EPA) and docosapentaenoic acid (DHA), which do not usually occur in terrestrial plants [40]. The technology enhances the nutritional value of the oilseeds for humans, and could also substantially reduce demand for fatty acids from wild-caught fisheries, which currently supply EPA and DHA in fishmeal and fish oil for the aquaculture industry and human dietary supplements. However, fatty acids are involved in key physiological functions in invertebrates and vertebrates. The inclusion of EPA and DHA in the fat profile of oilseeds proportionally reduces the availability of alpha-linolenic acid, which is essential for health, growth, cognition, and survival in terrestrial insects [41]. In cropping systems, these highly bioactive fatty acids would add a novel component to the diets of primary consumers, with potentially major impacts across food webs. For instance, butterfly larvae feeding on these crops develop into heavier adults but have smaller wings that are more likely to be deformed [42]. It is unclear whether regulatory agencies worldwide have examined the potential for these novel crops to have unintended consequences on animals, especially insects, in agricultural areas.

\section{Harnessing plant microbiomes for agricultural production and ecosystem restoration}

296 Plants host a diverse community of tightly associated microbes - their microbiome - which facilitates 297 tolerance of stress such as drought and enhances their growth and disease resistance [43]. 298 Manipulation of plant microbiomes has considerable potential to increase the success of ecosystem restoration actions [44] and improve agricultural yields and disease resistance [45]. To date, most biome manipulations have inoculated plants with a few beneficial microbial strains, whereas manipulating complex microbial communities largely has not been feasible [45]. Technological advances have recently reinvigorated this field. Several start-up companies are actively exploiting the 
plant microbiome, aided by increasingly cheap DNA sequencing and developments in analytical techniques such as machine learning. For example, Indigo Agriculture identified the microbiome of healthy cotton plants under drought conditions, and sells microbe-coated cotton seeds that have 11$15 \%$ greater yield during drought. AgBiome has altered crop microbiomes to combat fungal diseases, reducing the need for fungicides. Given demand for sustainable agricultural systems and mistrust of genetically modified organisms, elucidating the rules of functionally programmable plant microbiome assembly may lead to another revolution in agriculture. Effects on biological diversity may be both positive and negative, from reduced pesticide and fertiliser use, to agricultural expansion into areas formerly marginal for agriculture but rich in wildlife.

\section{Expansion of plantations and infrastructure into Indo-Malay islands}

Many Indo-Malay islands have high species richness and exceptional levels of endemism. However, only $2 \%$ of land in the region is formally protected, and annual rates of deforestation are increasing.

The average size of a palm oil plantation across the whole Indo-Malay Archipelago is currently approximately $1 \mathrm{~km}^{2}$, compared with $10 \mathrm{~km}^{2}$ in Borneo and $6 \mathrm{~km}^{2}$ in Papua New Guinea, where palm oil plantations are well-established [46]. However, there are signs of expanding infrastructure and industrialization of plantations across the region. For example, in Halmahera in Indonesia, industrial housing complexes accounted for $37 \%$ of major deforestation in 2014 , and deforestation increased by $250 \%$ in 2015 as industrial scale palm oil cultivation commenced. Across southeast Asia, commodity-driven deforestation accounts for $61 \%$ of tree cover loss [47], and former estimates of annual forest loss across the region were biased downwards. Although the damaging consequences of the expansion of palm oil plantations in the region are well-known, with global annual production 
predicted to grow by $1.7 \%$ each year until 2050 [48], the impacts of their spread into small, highly

biodiverse and fragile island systems have not been fully considered. The high levels of endemism in this region, especially on the small islands of Nusa Tenggara and Maluku, suggest that further palm oil plantation expansion could cause a substantial number of extinctions across the region.

Development of fisheries in the mesopelagic zone

334 The mesopelagic zone of the ocean extends from depths of 200 to $1000 \mathrm{~m}$, and this largely constrained exploitation of this zone by commercial fisheries. However, recent estimates of an abundant and virtually untapped biomass of mesopelagic fishes (as much as $10^{9}$ tonnes), coupled suggest that effects on marine life, food webs, and the global climate may be substantial [52]. 
351 Expanding human population and changing diets [53] are increasing demand for high-quality protein 352 from livestock, with associated environmental effects such as land-use change, loss of biodiversity, 353 nutrient enrichment, and emissions of greenhouse gases [54]. Novel livestock feed sources could 354 mitigate these environmental effects. One proposal is the use of industrially-produced microbial 355 protein to feed animals. Replacing $2 \%$ of livestock feed with microbial protein could decrease cropland area, nitrogen losses, and agricultural greenhouse gas emissions by more than 5\% [55]. The particular microbial protein production system used determines whether emissions and land-use change offsets are positive or negative. Microbial protein produced from natural gas or hydrogen could decouple production from cropland, reducing negative effects of cultivation but requiring considerable amounts of energy. Vegetable-based feedstocks such as sugar or biogas have fewer environmental benefits, requiring agricultural land to produce, and potentially increasing emissions of nitrogen and greenhouse gases. The global effects of production system displacement on human livelihoods also are unclear.

\section{Innovative insurance products to share costs and benefits of protecting natural assets}

367 Through sustainable management, ecosystems can provide major services to people [56]. There is an 368 effort to develop insurance products to cover valuable natural assets, analogous to the use of other 369 insurance schemes that protect assets, avoid financial loss, and provide funds for repairs [57]. This is 370 a novel development, as it is the natural assets themselves that are being insured against loss or 371 damage. In Mexico, such a scheme is being used to share the costs and benefits of protecting a 372 stretch of the Mesoamerican Reef. The Mexican government, along with local hotel owners, the 373 insurance industry, and The Nature Conservancy have developed an insurance product through a 374 trust fund called the Coastal Zone Management Trust. The Trust has two roles: to buy an insurance 
375 policy on a stretch of the reef, and to maintain the reef and local beaches. On the basis of a parametric 376 policy, where payment is triggered when a specified wind-speed is reached, the Trust will make funds 377 available to restore the reef and beach after a severe storm [58]. This type of innovative insurance 378 product could help protect and improve the health of other natural systems to the continued benefit 379 of people.

\section{Effects of noncompliance with the Montreal Protocol on global environmental governance}

383 Stratospheric levels of chlorofluorocarbon 11 (CFC-11), one of the most potent ozone-depleting compounds, have been declining much more slowly than expected [59]. This could slow the rate of reversal of the ozone hole, resulting in an increase in the amount of ultraviolet radiation reaching Earth, with negative effects on humans and other species. In 1987, the globally ratified Montreal Protocol on Substances that deplete the Ozone Layer introduced stepped limits on CFC production and use, culminating in a global ban by 2010. The recent trend in CFC levels raised concerns that CFCs may again be in illicit production. Further investigation provided evidence that CFC-11 is being used illegally in parts of China for the manufacture of foam insulation for the construction industry [60].

The Montreal Protocol has long been heralded as a rare success among international environmental treaties, and is the most successful example to date. The recent developments raise questions about the feasibility of enforcing multilateral agreements in general. Failure to resolve this apparent compliance challenge is likely to have profound effects on the future credibility of global environmental governance. 
Each annual horizon scan for global conservation issues identifies a diverse set of topics. Of the fifteen topics identified this year, many focus on advances or applications in technology or step changes in the demand for commodities, and the potential effects on the ecosystems supplying those resources. Most of the issues we identified this year, as in previous years, are new developments that could have direct or unintended environmental effects. Nevertheless, six of the developments could have either positive or negative consequences (or both): the capacity of Antarctic benthos to store carbon, options for addressing plastic pollution, regulation of gene-edited plants, harnessing plant microbiomes for agricultural production, industrial microbial feed production, and shinorine sunscreens. A number of these issues highlight the challenges of devising solutions to many conservation challenges. If the implementation of solutions, such as alternatives to plastics or sunscreens, are associated with unforeseen or uncertain negative consequences this can be a difficult message to communicate effectively to innovation funders, policy makers, and the general public. Only one issue (innovative insurance products) could be considered entirely positive for the conservation of biological diversity.

A recurring theme in our horizon scans over the last five years is the ability of the governments of 417 influential countries, such as China and the United States of America, to make policy or economic 418 decisions regarding infrastructure, trade, or agriculture that can result in global environmental 419 impacts. Such governmental decisions, for which the reasoning and timing can be opaque and 420 unpredictable, can have considerable influence over whether a new approach or technology is widely 421 adopted. Topics that fall into this area include cloud seeding and irrigation on the Tibetan Plateau, 422 the US government's decision not to regulate gene-edited plants, and, potentially, the planting of 
423 salt-tolerant rice, if international collaboration or state-backing drives spatially-extensive 424 deployment. Similar issues identified in previous horizon scans included ecological civilisation policies 425 in China, China's Belt and Road Initiative, and the erection of fences along national borders $[1,6,61]$. 426 The effects of these phenomena may increase if intergovernmental institutions become less 427 important. Indeed, decisions by the governments of influential countries will also determine the 428 effectiveness of global environmental governance or agreements, such as the Montreal Protocol 429 (1987) and the Paris Agreement of the United Nations Framework Convention on Climate Change 430 (2015).

432 Another striking aspect of the topics raised here is that many are associated with novel agricultural 433 technologies (gene-edited plants, new irrigation methods or infrastructure). This surely reflects a perceived urgency in meeting food demands for growing and enriching global populations, coinciding with a maturing biotechnology revolution. Past examples where agricultural innovation rapidly threatened wild animals have included the effects of diclofenac on vultures [62] and neonicotinoids on bees [63], with agricultural intensification responsible for continent-wide losses of species (e.g. 438 [64]. We previously identified the rapidly growing field of biotechnology as an area to watch [1], and these developments appear now to be increasingly likely, as gene editing technologies become more 440 effective and widely used, their products become more marketable, and reduced regulation makes 441 their large-scale deployment, maybe without adequate checks, more likely [65].

443 A challenge in our horizon-scanning process is deciding where on the spectrum from novel-uncertain 444 to established-certain we should target identification of issues. We aim to avoid both topics that are so speculative that they are unlikely to materialize, as well as those that are widely known or are unlikely to have major effects. We thus seek topics for which awareness is currently low, but evidence 
is sufficient to suggest that realization is plausible. Topics that were submitted this year, but

considered too uncertain included the use of sunscreen layers at the sea surface to protect coral reefs, the impacts of neo-protectionist trade policies, the effects of ocean acidification on phytotransferrin in diatoms [66], and the effects of daisy-chain gene drives on wildlife [67]. Because these issues were based solely on a single scientific publication or press release, there was a low level of evidence and high uncertainty as to whether substantial effects may result. However, we plan to revisit these topics in the future if more evidence emerges with which to evaluate them. Conversely, other submitted topics, such as the use of common species as substitutes for rare species in traditional medicine, the use of portable DNA tests to detect trade in illegal wildlife products, or the ban on sunscreens to protect reefs in Hawaii, were considered by the group to be too well-known for retention.

More than 70 experts from 46 organisations have participated in our annual horizon scans over the last ten years. Of the 150 topics identified from 2010 to 2019, 30 were related to effects of changes in energy production and resource use; 21 to social, political and economic changes; 16 to effects of climate change; 16 to changes in agriculture; 15 to changes in pollutants and toxicants (including greenhouse gases); and 12 to biotechnology and other technological advances. We classified topics as new technologies if they were new developments, but their potential effects are not yet clear or may be extensive, such as artificial life (2010, [7]) or the 3D printing revolution (2013, [68]). Other recurring topics included impacts on marine conservation (11 issues) or terrestrial conservation (nine issues), effects of emerging or re-emerging diseases (nine issues) and non-native invasive species (seven issues), and novel approaches to monitoring (four issues). Where feasible, we classified topics on the basis of their potential effects. For example, we included both methane 
venting from the ocean floor (2011, [69]) and rapid transformation of the Arctic benthos (2018, [8])

471 as effects of climate change.

472

473 We believe that these annual scans continue to identify emerging issues that are relevant to global

474 conservation and should be considered by researchers, policy makers and practitioners. In a

475 companion paper, we assess the issues identified in the first horizon scan [7], and investigate the

476 degree to which the issues have been realized or become greater priorities in the scientific and

477 policy agenda (Sutherland et al. in review).

\section{Acknowledgments}

480 This exercise was coordinated by the Cambridge Conservation Initiative and funded by the Natural 481 Environment Research Council and the Royal Society for the Protection of Birds. We are grateful to 482 everyone who submitted ideas to the exercise. We thank Beatriz Morales Nin and Erlend Moksness 483 (exploitation of the mesopelagic zone), Craig Macadam (effect on terrestrial food webs of transgenic 484 oilseed crops that produce omega 3 fatty acids), Ros Aveling and Gabriella Church (ecological effects 485 of options for reducing plastic pollution), and Hannah Becker (extensive release of mercury by 486 thawing permafrost) for suggesting issues presented in this paper. Thanks to the editor and 487 anonymous reviewer for efficient and useful comments on the manuscript. W.J.S. is funded by 488 Arcadia. X.L.R. was funded by BiodivERsA, C.L.S. was part-funded by the South African National 489 Research Foundation, L.V.D. by NERC (NE/N014472/1) and Z.J. by Basic Science Special Project of 490 MOST (2013FY110300 \& CAS NOXDA19050204).

\section{References}


1. Sutherland, W.J. et al. (2017) A 2017 horizon scan of emerging issues for global conservation and biological diversity. Trends Ecol. Evol. 32, 31-40

2. Larson, C. (2018) Asia's hunger for sand takes toll on ecology. Science 359 (6379), 964-965

3. WWF (2018) How blockchain \& a smartphone can stamp out illegal fishing and slavery in the tuna industry. 8 January 2018. http://www.wwf.org.au/news/news/2018/how-blockchainand-a-smartphone-can-stamp-out-illegal-fishing-and-slavery-in-the-tunaindustry\#gs.JHOAC4s

4. Figorilli, S. et al. A Blockchain Implementation Prototype for the Electronic Open Source Traceability of Wood along the Whole Supply Chain. Sensors 18, 3133.

5. European Parliament (2018) New fisheries rules: add a ban on electric pulse fishing, say MEPs. 16 January 2018. http://www.europarl.europa.eu/news/en/pressroom/20180112IPR91630/new-fisheries-rules-add-a-ban-on-electric-pulse-fishing-say-meps

6. Sutherland, W.J. et al. (2016) A horizon scan of global conservation issues for 2016. Trends Ecol. Evol. 31, 44-53

7. Sutherland, W.J. et al. (2010) A horizon scan of global conservation issues for 2010. Trends Ecol. Evol. 25, 1-7

8. Sutherland, W.J. et al. (2018) A 2018 horizon scan of emerging issues for global conservation and biological diversity. Trends Ecol. Evol. 33, 47-57

9. Sutherland W.J. et al. (2011) Methods for collaboratively identifying research priorities and emerging issues in science and policy. Methods Ecol. Evol. 2, 238-247

10. Mukherjee, N. et al. (2015) The Delphi technique in ecology and biological conservation: applications and guidelines. Methods Ecol. Evol. 6, 1097-1109

11. Danziger S. et al. (2011) Extraneous factors in judicial decisions. Proc Natl Acad Sci. USA 108, 12001-12006 

$558,219-222$.

13. Barnes D.K.A. (2017) Iceberg killing fields limit huge potential for benthic blue carbon in Antarctic shallows. Glob. Chang. Biol. 23, 2649-2659.

14. Barnes D.K.A. et al. (2018) Icebergs, sea ice, blue carbon and Antarctic climate feedbacks. Philos Trans A Math Phys Eng Sci. 376, 20170176.

15. Scheuhammer, A.M. et al. (2007). Effects of environmental methylmercury on the health of wild birds, mammals, and fish. $A M B I O, 36,12-19$.

16. Rieder, S.R. and Frey, B. (2013) Methyl-mercury affects microbial activity and biomass, bacterial community structure but rarely the fungal community structure. Soil Biol. Biochem. 64, 164-173.

17. Stern, G.A. et al. (2012) How does climate change influence arctic mercury? Sci. Tot. Environ. $414,22-42$.

18. Olson, C. et al. (2018) Mercury in Active-Layer Tundra Soils of Alaska: Concentrations, Pools, Origins, and Spatial Distribution. Global Biogeochem. Cycles 32, 1058-1073.

19. Schuster, P.F. et al. (2018) Permafrost Stores a Globally Significant Amount of Mercury. Geophys. Res. Lett. 45, 1463-1471.

20. Schuster, P.F. et al. (2011) Mercury Export from the Yukon River Basin and Potential Response to a Changing Climate. Environ. Sci. Technol. 45, 926.

21. Diaz-Silvarrey, L.S. et al. (2018) Monomer recovery through advanced pyrolysis of waste high density polyethylene (HDPE), Green Chem. 20, 1813-1823

22. Austin, H.P. et al. (2018) Characterization and engineering of a plastic-degrading aromatic polyesterase. Proc. Natl. Acad. Sci. 115(19), E4350-E4357. 
23. UNEP (2015) Biodegradable Plastics and Marine Litter. Misconceptions, concerns and impacts on marine environments. United Nations Environment Programme, Nairobi.

24. Yang, G. et al. (2018) Photosynthetic production of sunscreen shinorine using an engineered cyanobacterium. ACS synthetic biology 7, 664-671.

25. Downs, C.A. et al. (2016) Toxicopathological effects of the sunscreen UV filter, oxybenzone (benzophenone-3), on coral planulae and cultured primary cells and its environmental contamination in Hawaii and the US Virgin Islands. Arch. Environ. Contam. Toxicol. 70, 265288.

26. Becker, K. et al. (2016) Immunomodulatory effects of the mycrosporine-like amino acids shinorene and porphyra-334. Marine Drugs 14, 119.

27. Yang, Q. et al. (2018) The Query: The Feasibility of the Water Diversion Function of "Hongqi River". J. Nat. Res. 33, 893-898.

28. Foggin, J.M. (2018) Environmental Conservation in the Tibetan Plateau Region: Lessons for China's Belt and Road Initiative in the Mountains of Central Asia. Land, 7, 52.

29. Shan, Z. (2018) Why did some of those mega-projects which claimed to benefit human beings failed? Chinese National Geography 6, 14-21.

30. Chen, S. (2018) China needs more water. So it's building a rain-making network three times the size of Spain. South China Morning Post, 26 March 2018. https://www.scmp.com/news/china/society/article/2138866/china-needs-more-water-soits-building-rain-making-network-three

31. Lin J. and Singer P.W. (2018) China is using furnaces to manufacture 10 billion tons of rain. Popular Science, 11 April 2018. https://www.popsci.com/china-cloud-seeding-silver-iodidefurnace 
32. Zhou, Y. et al. (2018) The Receptor-like Cytoplasmic Kinase STRK1 Phosphorylates and Activates CatC, thereby Regulating $\mathrm{H} 2 \mathrm{O} 2$ Homeostasis and Improving Salt Tolerance in Rice. Plant Cell, 30, 1100-18.

33. Xinhua (2017) Saline soil rice experiment a success in China. Xinhuanet, 28 September 2017,

\section{http://www.xinhuanet.com//english/2017-09/28/c 136646404.htm}

34. Food and Agriculture Organization of the United Nations (2018) FAOSTAT Statistics

$$
\text { Database. FAO, Rome }
$$

35. Wang, S. J. et al. (2017) Research on saline-alkali soil amelioration with FGD gypsum.

$$
\text { Resourc. Conserv. Recycl. 121, 82-92. }
$$

36. Miao, C. et al. (2018) Mutations in a subfamily of abscisic acid receptor genes promote rice growth and productivity. PNAS 201804774

37. Zsögön, A. et al. (2018) De novo domestication of wild tomato using genome editing. Nature Biotech. doi:10.1038/nbt.4272

38. USDA (2018) Secretary Perdue Issues USDA Statement on Plant Breeding Innovation https://www.usda.gov/media/press-releases/2018/03/28/secretary-perdue-issues-usdastatement-plant-breeding-innovation

39. Court of Justice of the European Union (2018) Press Release No 111/18 Luxembourg, 25 July 2018. https://curia.europa.eu/jcms/upload/docs/application/pdf/2018-07/cp180111en.pdf

40. Usher, S. et al. (2017) Tailoring seed oil composition in the real world: optimising omega-3 long chain polyunsaturated fatty acid accumulation in transgenic Camelina sativa. Sci. Rep. 7 , 6570.

41. Colombo, S.M. et al. (2018) Potential for novel production of omega-3 long-chain fatty acids by genetically engineered oilseed plants to alter terrestrial ecosystem dynamics. Agricultural Systems 164, 31-37. 
42. Hixson, S.M. et al. (2016) Long-chain omega-3 polyunsaturated fatty acids have developmental effects on the crop pest, the cabbage white butterfly Pieris rapae. PLoS ONE 11, e0152264.

43. Rho, H. et al. (2017) Do endophytes promote growth of host plants under stress? A metaanalysis on plant-stress mitigation by endophytes. Microb. Ecol. 75, 407-418.

44. Harris, J. (2009) Soil Microbial Communities and Restoration Ecology: Facilitators or Followers? Science 325 (5940), 573-574

45. Finkel, O.M. et al. (2017) Understanding and exploiting beneficial plant microbes. Curr. Opin. Plant Biol. 38, 155-163.

46. Hughes, A.C. (2018) Have Indo-Malaysian forests reached the end of the road? Biol. Cons. 223, 129-137.

47. Curtis, P.G. et al. (2018) Classifying Drivers of Global Forest Loss. Science 361(6407), 11081111.

48. Meijaard, E. et al. (eds.) (2018) Oil palm and biodiversity. A situation analysis by the IUCN Oil Palm Task Force. IUCN Oil Palm Task Force Gland, Switzerland: IUCN.

49. Irigoien X. et al. (2014) Large mesopelagic fishes biomass and trophic efficiency in the open ocean. Nature Comms., 5, ncomms4271.

50. St. John M.A. et al. (2016) A dark hole in our understanding of marine ecosystems and their services: perspectives from the mesopelagic community. Front. Mar. Sci. 3, 31.

51. Prellezo R. (2018) Exploring the economic viability of a mesopelagic fishery in the Bay of Biscay. ICES J. Mar. Sci. fsy001, https://doi.org/10.1093/icesjms/fsy001

52. LaCapra V. (2018) Mission to the Twilight Zone; The urgent quest to explore one of Earth's hidden frontiers. Oceanus Magazine, 17 April 2018

http://www.whoi.edu/oceanus/feature/mission-to-the-ocean---s-twilight-zone 
53. Godfray, H.C.J. et al. (2018) Meat consumption, health, and the environment. Science, 361 (6399) eaam5324

54. Poore, J. and Nemecek T. (2018) Reducing food's environmental impacts through producers and consumers. Science 360(6392), 987-992.

55. Pikaar, I. et al. (2018) Decoupling Livestock from Land Use through Industrial Feed Production Pathways. Environ. Sci. Technol. 52, 7351-7359.

56. Eggermont H. et al. (2015) Nature-based solutions: new influence for environmental management and research in Europe. GAIA 24, $243-248$.

57. Tercek, M. (2018) Business To The Rescue: Insurance For Reef Restoration. Forbes, 8 March 2018. https://www.forbes.com/sites/marktercek/2018/03/08/business-to-the-rescueinsurance-for-reef-restoration/\#20ce9c773e0c.

58. The Nature Conservancy (2017) Insuring Nature to Ensure a Resilient Future. https://global.nature.org/content/insuring-nature-to-ensure-a-resilientfuture?src=r.v_insuringnature.

59. Montzka, S.A. et al. (2018) An unexpected and persistent increase in global emissions of ozone-depleting CFC-11. Nature 557(7705), 413.

60. EIA (2018) Blowing it: illegal production and use of banned CFC-11 in China's Foam blowing industry. Environmental Investigations Agency, London.

61. Sutherland W.J. et al. (2015) A horizon scan of global conservation issues for 2015. Trends Ecol Evol. 30, 17-24

62. Oaks, J.L. et al. (2004). Diclofenac residues as the cause of vulture population decline in Pakistan. Nature 427(6975), 630.

63. Woodcock, B.A. et al. (2016) Impacts of neonicotinoid use on long-term population changes in wild bees in England. Nature Comms. 7, 12459. 
64. Pe'er, G. et al. (2014) Agriculture policy. EU agricultural reform fails on biodiversity. Science 344(6188), 1090-1092.

65. Reeves, R.G. et al. (2018) Agricultural research, or a new bioweapon system? Science 362(6410), 35-37.

66. McQuaid et al. (2018) Carbonate-sensitive phytotransferrin controls high affinity iron uptake 640 in diatoms. Nature 555, 534-537

67. Noble, C. et al. (2016) Daisy-chain gene drives for the alteration of local populations. BioRxiv, 057307. Ecol Evol. 28, 16-22

69. Sutherland W.J. et al. (2011) A horizon scan of global conservation issues for 2011. Trends 646 Ecol. Evol. 26, 10-16 
647 Figure 1. The stages of the horizon scanning procedure used to identify the topics presented in this 648 paper. 